\title{
Traction Diverticulum of the Small Bowel with Enterolith as a Cause of Intestinal Obstruction
}

\author{
Mahir Gachabayov, MD, PhD; Lala Orujova, MD; and Kubach Kubachev, MD, PhD
}

A woman, aged 55 years, was admitted with a 2-day history of colicky abdominal pain, nausea, and vomiting. Her past medical history was significant for open sigmoidectomy for diverticulitis 9 years prior to admission and open adhesiolysis for small bowel obstruction 6 years prior to admission. On admission, the patient was stable; succussion splash and tenderness over the right lower quadrant on abdominal examination was present. Erect abdominal radiography revealed dilation of small bowel loops, and air fluid levels were revealed. Nonoperative management included restricting the patient to NPO, initiating intravenous fluids, and a placement of a nasogastric tube. Contrast meal was administered prior to the nasogastric tube placement. Nonoperative management failed to resolve the intestinal obstruction. The patient underwent laparotomy, which revealed traction diverticulum of the ileum $60 \mathrm{~cm}$ proximal to the ileocecal valve with enterolith causing intestinal obstruction (Figure 1). Small bowel resection was performed. The postoperative course was uneventful, and the patient was discharged on postoperative day 11. On follow-up 2 months later, the patient was doing well.

Even though several cases of traction diverticula of the esophagus, duodenum, and colon have been described in the literature, to the best of our knowledge, this is the first case reporting traction diverticulum of the small intestine. The rarity of this clinical entity could probably be explained by anatomic mobility of the small intestine. Therefore, long-term traction on the small bowel wall can only arise in the context of diffuse adhesions.

Congenital diverticula of the gastrointestinal tract can be encountered in various sites from the pharynx to colon. ${ }^{1,2}$ The most common congenital diverticulum is Meckel's diverticulum, which is also the most common gastrointestinal anomaly. ${ }^{3}$ A diverticulum is considered true when it involves all three layers of intestinal wall (including muscularis and adventitia.) False diverticula result from the herniation of only the mucosal and submucosal layers through the points with minor resistance to intraluminal pressure. Congenital gastrointestinal diverticula are always true diverticula. ${ }^{3}$ Acquired diverticula morphologically can be divided into both true and false diverticula. Pulsion diverticula are false diverticula (or pseudodiverticula), whereas traction diverticula are true diverticula. The vast majority of acquired jejunoileal diverticula are pulsion pseudodiverticula. ${ }^{5}$

The etiopathogenesis of pseudodiverticula formation could be described as increased intraluminal pressure as a result of small bowel motility disorders, connective tissue disorders, or neuromuscular conduction disorders against the sites of minimal resistance, such as sites where blood vessels enter the submucosal layer, perforating the muscular layer. ${ }^{5}$ The association of various systemic diseases, such as Marfan syndrome, Fabry's disease, and Cronkhite-Canada syndrome with small bowel diverticulosis have been previously reported. $^{68}$

Acquired small bowel diverticula are usually asymptomatic and are found incidentally during radiology or laparotomy done for another abdominal condition. In 29\% of cases, patients can present with "flatulent dyspepsia triad" including epigastric pain, abdominal discomfort, and postprandial flatulence. ${ }^{9}$ In up to $30 \%$ of cases, complications such as acute diverticulitis, perforation, intestinal obstruction, and bleeding can emerge. ${ }^{10}$
Corresponding Author: Mahir Gachabayov, MD, PhD, Vladimir City Clinical Hospital of Emergency Medicine, Department of Abdominal Surgery, 600022, Stavrovskaya Street, 6-73 ,Vladimir Russia ,Tel: +7 (915) 790-1632 Email: gachabayovmahir@mail.ru
Received:April 25, 2018

Revised: October 11, 2018

Accepted: October 24, 2018

doi: $10.3121 / \mathrm{cmr} .2018 .1436$ 


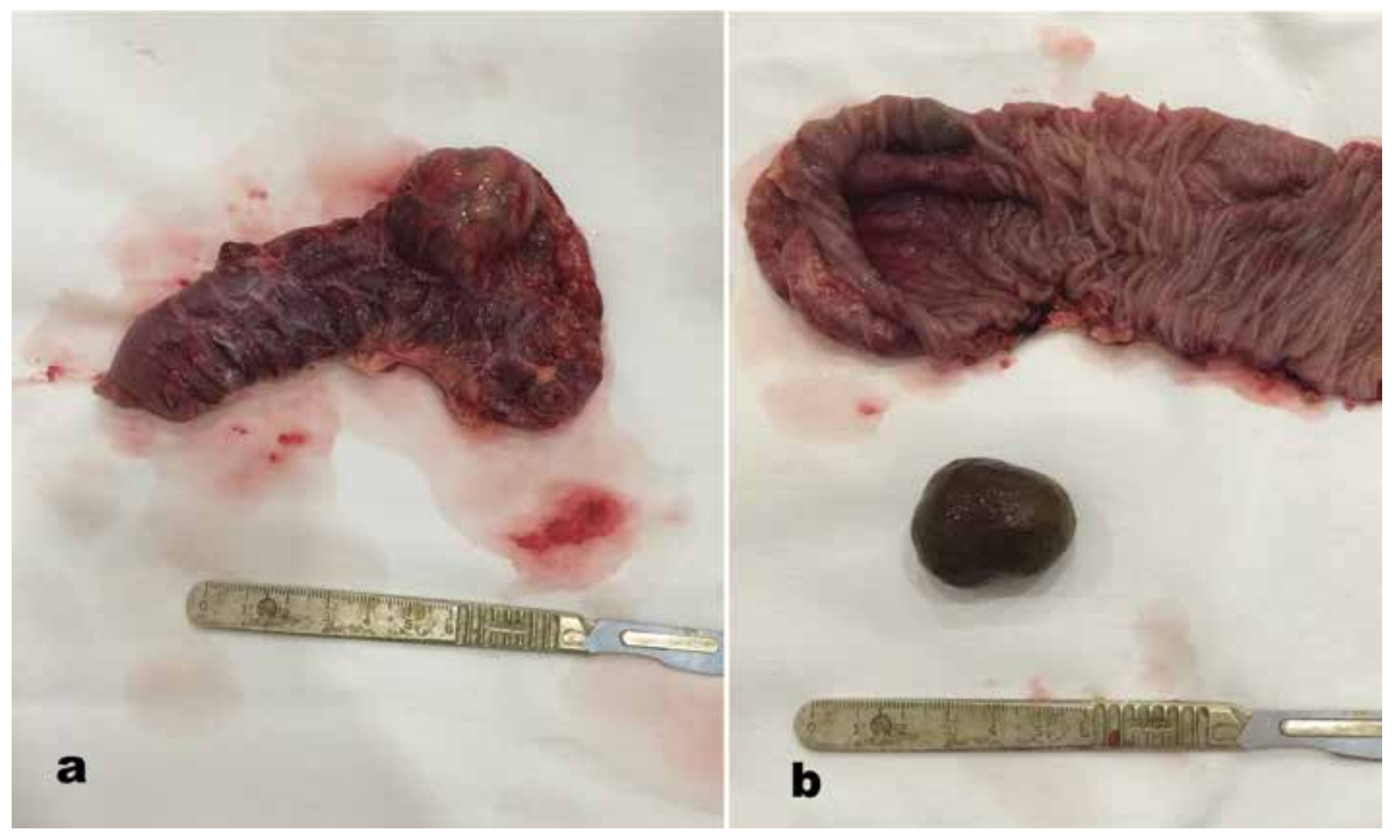

Figure 1. Resected small bowel with traction diverticulum and enterolith. (a) Traction diverticulum of the ileum (3x4 $\mathrm{cm})$ and (b) the enterolith $(3 \times 2 \mathrm{~cm})$.

The most important modality for diagnosis of small bowel diverticulosis is contrast-enhanced computed tomography (CT), which reveals diverticula as discrete round or ovoid, contrast, fluid or air-filled structures outside the expected lumen of the small bowel, with a smooth, barely discernible wall and no recognizable small-bowel folds. ${ }^{11}$

In cases where surgically treated small bowel diverticula experience complications, additional surgical treatment may be required. However, several cases of conservatively treated jejunal diverticulum perforation, including antibiotics and CT-guided percutaneous abscess drainage, have been reported. ${ }^{12}$ If diverticula involve a long intestinal segment, as commonly happens, the resection should be limited to the perforated or inflamed intestinal segment to avoid creating a short bowel syndrome. ${ }^{13}$

Bowel obstruction can emerge by various mechanisms, such as volvulus at the site of diverticulum, intussuseption of diverticulum, stenosis due to diverticulitis, extrinsic compression of the small bowel by a large diverticulum, and enterolith impaction. ${ }^{10,13}$ In the proximal small bowel with acidic $\mathrm{pH}$, enteroliths may form as a result of precipitation of bile salts deconjugated by bacteria. ${ }^{10}$ In the distal small bowel, enterolith formation is a result of debris accumulation in sites of stagnation such as diverticulum.
To conclude, traction diverticulum of the small bowel is an acquired true diverticulum formed as a result of long-term continuous traction of a fixed small bowel by adhesions or inflamed surrounding tissues. Enteroliths can be formed in the diverticular sac of the distal small bowel due to stagnation.

\section{References}

1. Rashid F, Aber A, Iftikhar SY. A review on gastric diverticulum. World J Emerg Surg. 2012;7(1):1.

2. Jeppesen GA, Willerth M. Perforated congenital diverticulum of the sigmoid colon. J Pediatr Surg. 2002;37(11):E35.

3. Gachabayov M, Abdullaev E, Babyshin V, Abdullaev A. Recurrent intestinal obstruction due to Meckel's diverticulum: A case report. Edorium J Gastrointest Surg. 2015;2:1-5.

4. Hughes LE. Postmortem survey of divericular disease of the colon. Gut. 1969;10:336.

5. Kongara KR, Soffer EE. Intestinal motility in small bowel diverticulosis: a case report and review of the literature. $\mathrm{J}$ Clin Gastroenterol. 2000;30(1):84-86.

6. Shapira O, Mavor E, Simon D, Rothstein H, Pfeffermann R. Multiple giant gastrointestinal diverticula complicated by perforated jejunoileal diverticulitis in Marfan syndrome. Dig Surg. 1992;9(1):58-60.

7. Friedman LS, Kirkham SE, Thistlethwaite JR, Platika D, Kolodny EH, Schuffler MD. Jejunal diverticulosis with perforation as a complication of Fabry's disease. Gastroenterology. 1984;86(3):558-563.

8. Cunliffe WJ, Anderson J. Case of cronkhite-Canada syndrome with associated jejunal diverticulosis. Br Med J. 1967;4(5579):601-602. 
9. Rodriguez HE, Ziauddin MF, Quiros ED, Brown AM, Podbielski FJ. Jejunal diverticulosis and gastrointestinal bleeding. J Clin Gastroenterol. 2001;33(5):412-414.

10. Akhrass R, Yaffe MB, Fischer C, Ponsky J, Shuck JM. Smallbowel diverticulosis: perceptions and reality. J Am Coll Surg. 1997;184(4):383-388.

11. Fintelmann F, Levine MS, Rubesin SE. Jejunal diverticulosis: findings on CT in 28 patients. AJR Am J Roentgenol. 2008;190(5):1286-1290.

12. Novak JS, Tobias J, Barkin JS. Nonsurgical management of acute jejunal diverticulitis: a review. Am J Gastroenterol. 1997;92(10):1929-1931.

13. Falidas E, Vlachos K, Mathioulakis S, Archontovasilis F, Villias C. Multiple giant diverticula of the jejunum causing intestinal obstruction: report of a case and review of the literature. World J Emerg Surg. 2011;6(1):8.

\section{Author Affiliations}

Mahir Gachabayov, MD, PhD*; Lala Orujova, $M D^{*}$, and

Kubach Kubachev, $M D, P h D^{*}$

* Department of Surgery named after N.D. Monastyrski, North-Western State Medical Academy named after I.I.

Mechnikov, Saint Petersburg, Russia 